\title{
Prevalência da paralisia cerebral em neonatos de mães acometidas por Zika vírus:
}

\section{Uma revisão integrativa da literatura}

\author{
Prevalence of cerebral palsy in neonates of mothers affected by Zika virus: An integrative literature \\ review
}

Prevalencia de la parálisis cerebral en neonatos de madres afectadas por el virus Zika: Una revisión integrativa de la literatura

Recebido: 20/05/2021 | Revisado: 28/05/2021 | Aceito: 31/05/2021 | Publicado: 14/06/2021

\author{
Larissa Thais Cruz \\ ORCID: https://orcid.org/0000-0003-1684-7655 \\ Centro Universitário de Patos, Brasil \\ E-mail: larissathaiscruz@gmail.com \\ Osman Batista de Oliveira Filho \\ ORCID: https://orcid.org/0000-0002-4850-0667 \\ Centro Universitário de Patos, Brasil \\ E-mail: osmanbmf@ hotmail.com \\ Milena Nunes Alves de Sousa \\ ORCID: https://orcid.org/0000-0001-8327-9147 \\ Centro Universitário de Patos, Brasil \\ Faculdade São Francisco da Paraíba, Brasil \\ E-mail: milenanunes@ fiponline.edu.br
}

\begin{abstract}
Resumo
Objetivo: Determinar, a partir de uma revisão integrativa da literatura, a prevalência de paralisia cerebral em neonatos com mães acometidas por Zika vírus no Brasil. Metodologia: Foram utilizados artigos na íntegra presentes nas bases dados Medical Publications (PubMed) e Literatura Latino-americana e do Caribe em Ciências da Saúde (LILACS). Para a busca, utilizaram-se os descritores: Infecção por Zika virus, Zika virus, recém-nascido e paralisia cerebral; obtidos de acordo com os Descritores de Ciências da Saúde (DeCS), tendo como operador booleano "E/ AND". Posteriormente a aplicação dos critérios de inclusão definidos acima, nove artigos foram selecionados para revisão. Resultados: Em relação ao local de realização do estudo, 77,78\% foram realizados na região Nordeste do país. Um dos estudos teve uma amostra de 538 indivíduos. A prevalência das paralisias cerebrais associadas à infecção congênita pelo zika vírus variou de $15,2 \%$ a $100 \%$. Conclusão: Conclui-se que há uma alta prevalência de casos de neonatos de mães acometidas por ZIKV com paralisia cerebral. Estes dados reforçam a necessidade de serviços de intervenção precoce e planejamento de recursos para apoiar essas famílias em cuidados de saúde e ambientes comunitários no Brasil.
\end{abstract}

Palavras-chave: Recém-nascido; Infecção por Zika vírus; Paralisia cerebral.

\begin{abstract}
Objective: To determine, from an integrative literature review, the prevalence of cerebral palsy in neonates with mothers affected by Zika virus in Brazil. Methodology: Full articles from the Medical Publications (PubMed) and Latin American and Caribbean Literature in Health Sciences (LILACS) databases were used. For the search, the descriptors were used: Infection by Zika virus, Zika virus, newborn and cerebral palsy; obtained according to the Health Sciences Descriptors (DeCS), with the Boolean operator "E / AND". After applying the inclusion criteria defined above, nine articles were selected for review. Results: Regarding the place where the study was carried out, $77.78 \%$ were carried out in the Northeast region of the country. One of the studies had a sample of 538 individuals. The prevalence of cerebral palsy associated with congenital Zika virus infection ranged from $15.2 \%$ to $100 \%$. Conclusion: It is concluded that there is a high prevalence of cases of neonates of mothers affected by ZIKV with cerebral palsy. These data reinforce the need for early intervention services and resource planning to support these families in healthcare and community settings in Brazil.
\end{abstract}

Keywords: Infant; Newborn; Zika virus infection; Cerebral palsy.

\section{Resumen}

Objetivo: Determinar, a partir de una revisión integradora de la literatura, la prevalencia de parálisis cerebral en recién nacidos de madres afectadas por el virus del Zika en Brasil. Metodología: Se utilizaron artículos completos de las bases de datos Publicaciones médicas (PubMed) y Literatura latinoamericana y caribeña en ciencias de la salud 
(LILACS). Para la búsqueda se utilizaron los descriptores: Infección por virus Zika, virus Zika, recién nacido y parálisis cerebral; obtenido según los Descriptores de Ciencias de la Salud (DeCS), con el operador booleano "E / AND". Después de aplicar los criterios de inclusión definidos anteriormente, se seleccionaron nueve artículos para su revisión. Resultados: En cuanto al lugar donde se realizó el estudio, el 77,78\% se realizó en la región Nordeste del país. Uno de los estudios tuvo una muestra de 538 individuos. La prevalencia de parálisis cerebral asociada con la infección congénita por el virus del Zika osciló entre el 15,2\% y el 100\%. Conclusión: Se concluye que existe una alta prevalencia de casos de neonatos de madres afectadas por ZIKV con parálisis cerebral. Estos datos refuerzan la necesidad de servicios de intervención temprana y planificación de recursos para apoyar a estas familias en entornos comunitarios y de atención médica en Brasil.

Palabras clave: Recién nacido; Infección por el virus del Zika; Parálisis cere.

\section{Introdução}

O vírus Zika (VZIK) é um arbovírus composto de RNA da família Flaviviridae (gênero Flavivirus), que é a mesma família que inclui o vírus da dengue e chikungunya. Ele é transmitido vetorialmente por mosquitos da espécie Aedes aegypti, que também transmite febre amarela, dengue e chikungunya (Duarte et al., 2018; Werner Jr, 2019; Pereira, Araújo Júnior, Werner, \& Monteiro, 2020). Assim como nas outras arboviroses, o VZIK participa de um ciclo de transmissão complexo entre primatas e mosquitos, tendo o homem como hospedeiro ocasional e não intencional. O ritmo de urbanização nas últimas décadas acarretou num acúmulo de milhões de habitantes em diversas cidades. A vulnerabilidade social presente nesses locais pode ter contribuído para o aumento do número de casos (Werner Jr, 2019).

O VZIK foi detectado em 1952 na Nigéria (Macnamara, 1954). No Brasil, foi identificado pela primeira vez em 2015, após teste de soro de pacientes que apresentavam sintomas semelhantes aos da dengue (Campos, Bandeira, \& Sardi, 2015). A maioria das infecções pelo VZIK são assintomáticas (Duffy et al., 2009), porém, quando a doença clínica ocorre, ela geralmente é leve, com sintomas característicos de erupção maculopapular, febre, artralgia e/ou conjuntivite não purulenta (Hills, Fischer, \& Petersen, 2017; Xavier, Kanaan, Bozzi, \& Amaral, 2017). Os sintomas menos comuns incluem: dor abdominal, constipação, diarreia, tontura, aftas, fotofobia, náusea, vômito, anorexia e dor retro-orbital (Xavier et al., 2017).

Para o diagnóstico, deve ser feita a avaliação cuidadosa da infecção em relação aos parâmetros clínicos e paraclínicos (hematológicos). Além disso, o reverse transcription-polymerase chain reaction (RT-PCR) deve ser realizado para detecção de VZIK em conjunto com os dados clínicos, pois é considerado padrão-ouro, com alta especificidade e sensibilidade (Javanian, Masrour-Roudsari, \& Ebrahimpour, 2018). Se o resultado for negativo em amostras de sangue e urina, a possibilidade de infecção não pode ser excluída pelo teste de RT-PCR. Em casos de suspeita clínica em áreas endêmicas, é necessária a realização de rastreamento de anticorpos, quando o RT-PCR não confirmar a infecção (Xavier et al., 2017).

O tratamento da infecção pelo VZIK é de suporte e não há terapia específica, assim como em outros arbovírus. Em casos sintomáticos com febre e mialgia, recomenda-se o uso de analgésicos e antipiréticos, como paracetamol e dipirona. Em caso de prurido, os anti-histamínicos podem ser administrados com segurança (Lopes, Miyaji, \& Infante, 2016).

Outras formas de transmissão incluem a via sexual, intrauterina, perinatal, exposição em laboratório e provavelmente transfusão de sangue (Besnard, Lastere, Teissier, Cao-Lormeau, \& Musso, 2014; Barjas-Castro et al., 2016; Melo et al., 2016a; Melo et al., 2016b; Russel et al., 2017). A transmissão da mãe para o feto é a forma de transmissão mais preocupante, pois o vírus tem efeito teratogênico e pode atravessar a placenta em qualquer trimestre da gestação (Melo et al., 2016a; Melo et al., 2016b). Em estudo observacional prospectivo com gestantes, foi estimado que mais de $40 \%$ desses casos apresentaram sintomas de referida infecção (Brasil,P,et al, 2016).

As células progenitoras neurais são o principal alvo do VZIK, o que explica a extensão das alterações do sistema nervoso central fetal encontrada em estudo de neuroimagem (Mehrjard et al., 2017). A infecção por ZIKV durante a gravidez pode causar resultados adversos, como perda fetal, microcefalia congênita ou outras anomalias cerebrais graves (Melo et al., 
2016a; Melo et al., 2016b). A Síndrome de Guillain-Barré e casos raros de encefalopatia, meningoencefalite, mielite, uveíte, parestesia e trombocitopenia grave também foram relatados após a infecção (Cao-Lormeau t al., 2016; Carteaux et al., 2016; Furtado, Espósito, Klein, Teixeira-Pinto, \& da Fonseca, 2016; Mécharles et al., 2016; Rozé et al., 2016; Sharp et al., 2016). Outras anormalidades do sistema nervoso fetal incluem ventriculomegalia e calcificações intracranianas (Pereira et al., 2020).

A microcefalia é definida como um perímetro cefálico com mais de dois desvios padrão abaixo da média para idade e sexo (World Health Organization, 2016). Nesses casos, as alterações que podem estar presentes são déficit intelectual, epilepsia, hipertonia, atraso no desenvolvimento de linguagem e/ ou motor, estrabismo e outras desordens oftalmológicas, cardíacas, renais e do trato urinário, até mesmo paralisia cerebral (Brunoni et al., 2016; Fauce, \& Morens, 2016). A literatura ainda é escassa em relação aos casos de recém-nascidos com paralisia cerebral de mães acometidas pelo VZIK. Dessa forma o objetivo do presente estudo foi determinar, a partir de uma revisão integrativa da literatura, a prevalência de paralisia cerebral em neonatos com mães acometidas por Zika vírus no Brasil.

\section{Metodologia}

Para atender ao objetivo proposto, optou-se por realizar uma revisão integrativa da literatura. Para isso, foram observadas seis diretrizes pré-estabelecidas em um protocolo de pesquisa: 1) escolha do tema e definição da hipótese ou questionamento norteador; 2) estabelecimento dos critérios para inclusão e exclusão de estudos para seleção da amostra; 3 ) definição das informações a serem extraídas da amostra; 4) avaliação/análise crítica dos estudos incluídos na amostra; 5) discussão e interpretação dos resultados e 6) apresentação da revisão de forma objetiva e clara (Mowbray, Wilkinson, \& Tse, 2014).

Na primeira etapa, foi estabelecido o tema a partir da seguinte questão norteadora: Qual a prevalência de paralisia cerebral em neonatos com mães acometidas por Zika vírus no Brasil? Para a etapa seguinte, foram estabelecidos os seguintes critérios de inclusão: artigos científicos observacionais publicados em língua portuguesa ou inglesa, disponíveis na íntegra, sem restrição de ano, que avaliaram a prevalência de paralisia cerebral em neonatos com mães acometidas por Zika vírus.

Foram utilizadas as bases dados Medical Publications (PubMed) e Literatura Latino-americana e do Caribe em Ciências da Saúde (LILACS). Para a busca, utilizaram-se os descritores: Infecção por Zika virus, Zika virus, recém-nascido e paralisia cerebral; obtidos de acordo com os Descritores de Ciências da Saúde (DeCS), tendo como operador booleano "E/ AND”. Foram excluídos estudos de caso, revisões da literatura, relatos de experiência, monografias, dissertações, teses, estudos in vitro, estudos ex vivo e artigos duplicados, além de estudos que não se relacionavam com o tema.

As buscas foram realizadas no dia 01 de março de 2021, sendo localizados um total de 1.349 publicações, sendo 1.134 na base de dados PubMed e 215 no LILACS (Tabela 1). 
Tabela 1. Método de pesquisa para levantamento de estudos para esta revisão integrativa. Patos, PB, Brasil, 2021.

\begin{tabular}{|c|c|c|c|}
\hline \multirow[t]{2}{*}{ Descritores } & \multicolumn{3}{|c|}{ Bases de Dados } \\
\hline & Pubmed & LILACS & Total \\
\hline Zika virus E Paralisia Cerebral & 00 & 00 & 00 \\
\hline Zika virus AND Cerebral Palsy & 17 & 01 & 18 \\
\hline Infecção por Zika virus E Paralisia Cerebral & 00 & 00 & 00 \\
\hline Zika virus infection AND Cerebral palsy & 13 & 00 & 13 \\
\hline Zika virus E recém-nascido & 00 & 61 & 61 \\
\hline Zika virus AND infant, newborn & 561 & 60 & 621 \\
\hline Infecção por Zika virus E recém-nascido & 00 & 46 & 46 \\
\hline Zika virus infection AND infant, newborn & 543 & 47 & 590 \\
\hline Número total de artigos & 1.134 & 215 & 1.349 \\
\hline
\end{tabular}

Fonte: Dados de Pesquisa (2021).

Após a identificação nas bases de dados, foram aplicados os filtros de pesquisa referentes ao período de publicação e integridade do documento, e, em seguida, foram eliminados os estudos duplicados, totalizando 1.225 artigos. Em seguida, esses passaram por uma análise criteriosa do título e resumo, levando a serem excluídos 25 artigos, mantendo-se, assim, para leitura do texto na íntegra, 26 artigos. Posteriormente a aplicação dos critérios de inclusão, nove artigos constituíram a amostra desta revisão (Figura 1).

Figura 1. Fluxograma do processo de seleção dos artigos incluídos na revisão integrativa.

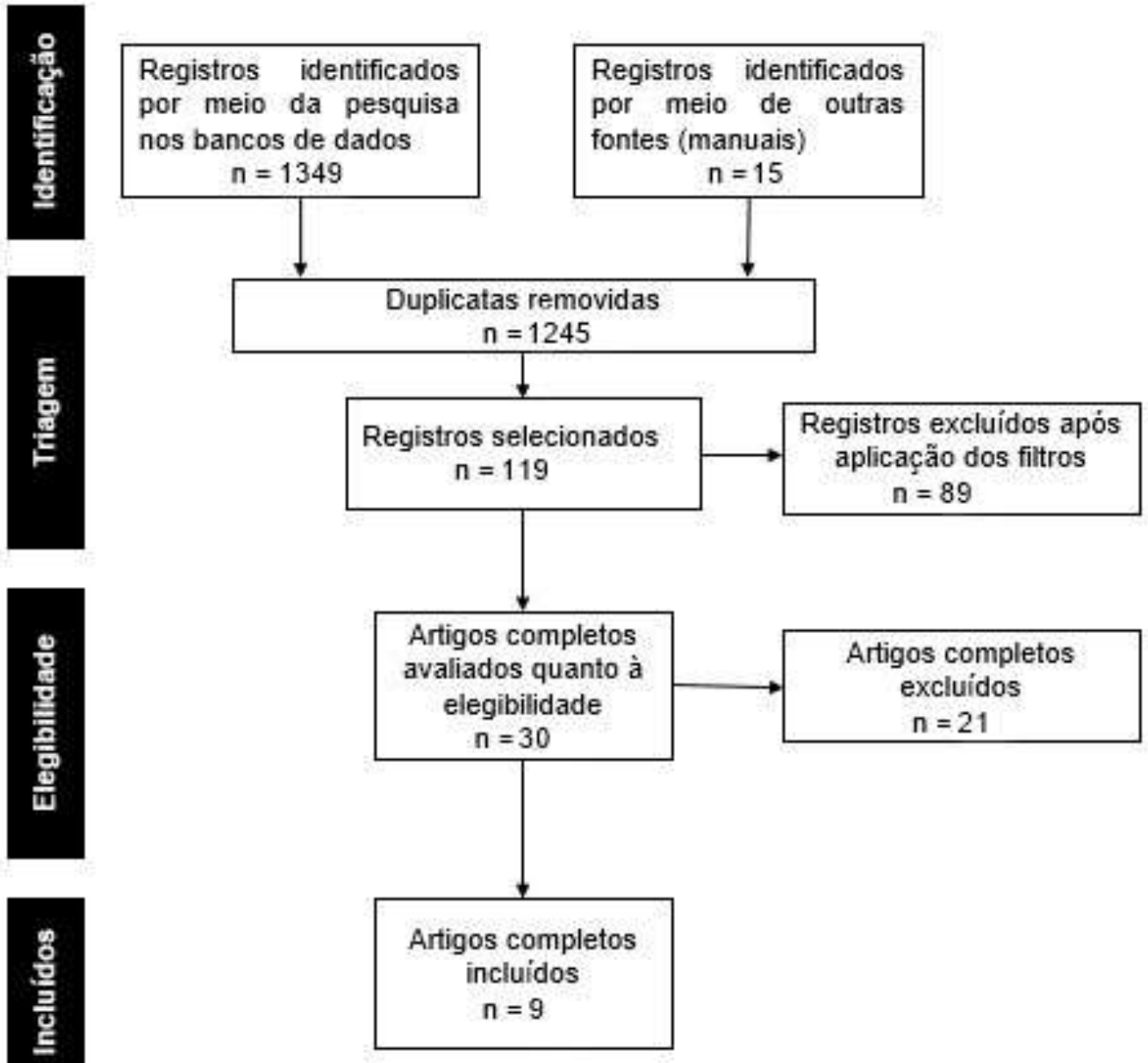

Fonte: Dados de Pesquisa (2021). 
Para terceira etapa, realizaram-se leituras exploratórias para coleta das informações consideradas pertinentes, tendo como base a questão norteadora e o objetivo do estudo. A partir disso, os dados retirados do texto foram organizados em um quadro contendo os seguintes dados: autores e ano de publicação; locais de realização do estudo; amostra; casos com paralisia cerebral.

Com a coleta das informações concluída, procedeu-se com as últimas etapas da pesquisa. Os estudos foram avaliados de forma crítica e criteriosa, sendo submetidos à análise qualitativa. $\mathrm{O}$ uso de quadros, contendo dados que serão apresentados nos resultados e discussão, permitiu que os conhecimentos fossem sintetizados, tornando-os mais acessíveis. Assim, pode-se levantar o conteúdo necessário para determinar a prevalência de paralisia cerebral em neonatos com mães acometidas por Zika vírus no Brasil e no mundo.

\section{Resultados}

Este estudo tratou-se de uma revisão integrativa da literatura de nove estudos observacionais, sendo todos prospectivos. Em relação ao local de realização do estudo, 77,78\% foram realizados na região Nordeste do país. Um dos estudos teve uma amostra de 538 indivíduos. A prevalência das paralisias cerebrais associadas à infecção congênita pelo zika vírus variou de $15,2 \%$ a $100 \%$ (Quadro 1).

Quadro 1. Distribuição dos estudos selecionados para esta revisão.

\begin{tabular}{|c|c|c|c|c|}
\hline Autores & Local & Amostra & Idades & $\begin{array}{c}\text { Casos com paralisia } \\
\text { cerebral }\end{array}$ \\
\hline $\begin{array}{l}\text { Satterfield-Nash et al. } \\
(2017)\end{array}$ & Paraíba-Brasil & 19 & 19-24 meses & $74 \%$ \\
\hline Ferreira et al. (2018) & Paraíba e Natal - Brasil & 34 & $21,2 \pm 7,3$ meses & $\begin{array}{c}100 \% \text { deficiência } \\
\text { completa em funções } \\
\text { mentais da linguagem }\end{array}$ \\
\hline Carvalho et al. (2019) & Nordeste - Brasil & 538 & 4,8 meses & $15,2 \%$ \\
\hline Einspieler et al. (2019) & $\begin{array}{c}\text { Belo Horizonte e Rio de Janeiro } \\
\text { - Brasil } \\
\text { Áustria }\end{array}$ & 56 & 14 semanas & $60,71 \% *$ \\
\hline Marques et al. (2019) & Rio de Janeiro - Brasil & 39 & 6-18 meses & $89,7 \%$ \\
\hline Melo et al. (2020) & Paraíba - Brasil & 59 & 14,7 meses & $81 \%$ \\
\hline Carvalho et al. (2020a) & Salvador - Brasil & 69 & 23-32 meses & $100 \% *$ \\
\hline Ventura et al. (2020) & Natal - Brasil & 77 & 11-24 meses & $100 \% *$ \\
\hline Takahashi et al. (2021) & Maranhão - Brasil & 36 & 25,6 meses & $100 \%$ \\
\hline
\end{tabular}

*Todos os participantes incluídos tinham paralisia cerebral associada à infecção congênita por vírus Zika.

Fonte: Dados de Pesquisa (2021).

\section{Discussão}

Em maio de 2015, o Brasil relatou a transmissão autóctone do VZIK por mosquito (Pan American Health Organization, 2017). Em novembro no mesmo ano, uma epidemia de microcefalia estava em curso no Brasil, posteriormente atribuída à infecção congênita pelo vírus (Pereira et al., 2019). Diversas infecções maternas podem causar perdas fatais ou malformações - principalmente no início da gravidez -, e a infecção congênita relacionada ao vírus Zika tem características semelhantes. Seus efeitos, entretanto, são teratogênicos, o que diferencia em relação a outras infecções congênitas (Pereira et al., 2019). 
De novembro de 2015 a abril de 2018, foram identificadas no Brasil 15.874 crianças com suspeita de distúrbios do desenvolvimento, presumivelmente relacionados ao VZIK ou outras infecções congênitas, 59,8\% nos estados do Nordeste. Salvador, capital do estado da Bahia, é a cidade mais populosa da região e com o maior número absoluto de casos confirmados (Brasil, 2018). Evidências indicam que o vírus pode ser transmitido verticalmente (Mlakar et al., 2016) e está associado com dano cerebral no feto, resultando na síndrome congênita (Melo et al., 2016a; Melo et al., 2016b; Moore et al., 2017).

A síndrome congênita do Zika (CZS) foi recentemente descrita após o surto de microcefalia relacionada ao vírus no Brasil, entre 2015 e 2016 (Carvalho et al., 2020b). A descrição inicial incluía as seguintes características: microcefalia grave e crânio parcialmente colapsado; características típicas de neuroimagem, incluindo atrofia cerebral e calcificações subcorticais; anormalidades oculares, com cicatriz macular e manchas retinianas pigmentares focais; artrogripose; e hipertonia grave precoce (Moore et al., 2017). Relatórios anteriores indicaram que a paralisia cerebral faz parte do espectro da síndrome congênita de VZIK (Pessoa et al., 2018).

A paralisia cerebral é representada por um grupo de distúrbios caracterizados por alteração de movimento, postura e tônus. Os distúrbios são decorrentes de danos não evolutivos do sistema nervoso central, que impedem o pleno desenvolvimento desse sistema ainda no útero, durante o parto ou nos primeiros anos de vida (Menezes, Santos, \& Alves, 2017). Na acepção dos referidos pesquisadores, o dano não é progressivo e enfraquece de forma variável a coordenação da ação muscular, resultando na incapacidade da criança de manter posturas e realizar movimentos normais, podendo, com o passar do tempo, ter alterações em suas manifestações clínicas.

No presente estudo, dois trabalhos tiveram $100 \%$ dos neonatos de mães infectadas por VZIK com paralisia cerebral, pois as crianças com essa condição foram colocadas nos critérios de inclusão (Carvalho et al., 2020a; Ventura et al., 2020). Carvalho et al. (2020a), como o objetivo de descrever o resultado do neurodesenvolvimento de 2 anos em crianças com paralisia cerebral associada ao VZIK congênito e explorar as variáveis associadas a uma apresentação mais grave, observaram que a paralisia cerebral relacionada ao Zika congênito evolui com grave prejuízo motor, cognitivo e de linguagem, o que corrobora os achados de acompanhamento de 1 ano. Os autores concluíram ainda que O perímetro cefálico ao nascer, artrogripose e epilepsia no primeiro ano de vida associaram-se a um pior resultado e podem ser considerados marcadores de prognóstico, sugerindo assim que essas descobertas são importantes para o planejamento do programa de neurorreabilitação, orientação dos pais e estudos prognósticos futuros (Carvalho et al., 2020a).

De forma semelhante, Ventura et al. (2020), em seu estudo, com o objetivo de avaliar o desenvolvimento motor grosso de crianças com infecção congênita pelo VZIK nos primeiros 2 anos de vida, foi observado que, apesar de mostrar algum progresso motor durante os primeiros 18 meses de vida, essas crianças com infecção congênita presumida por vírus e paralisia cerebral apresentaram comprometimento motor grave aos dois anos de idade.

No estudo de Carvalho et al. (2019), foram incluídas inicialmente 538 crianças com microcefalia ou infecção congênita pelo VZIK, onde foram selecionadas apenas 82 crianças com paralisia cerebral associada a provável infecção. Neste estudo, a maioria dos indivíduos tinha microcefalia congênita grave (62,0\%), paralisia cerebral espástica (96,3\%), epilepsia (63,4\%), ausência de reações posturais esperadas (93,2\%), persistência anormal de reflexos primitivos (94,7\%) e anormalidades graves de neuroimagem, predominantemente calcificações (97,6\%). Os autores sugeriram ainda que o perímetro cefálico pode ser um marcador de prognóstico entre essas crianças.

Satterfield-Nash et al. (2017) enfatizam que os resultados de seu estudo fornecem informações sobre os desafios contínuos enfrentados por crianças com síndrome congênita grave do VZIK e que essas crianças exigirão cuidados especializados de médicos e cuidadores à medida que envelhecem. Para os autores, essas descobertas permitem antecipar as necessidades de serviços médicos e sociais das crianças afetadas e suas famílias, incluindo serviços de intervenção precoce e 
planejamento de recursos para apoiar essas famílias em cuidados de saúde e ambientes comunitários no Brasil, nos Estados Unidos e em outros países.

Em coorte realizada por Marques et al. (2019), com objetivo de avaliar as trajetórias motoras grossas e a frequência de paralisia cerebral em crianças com síndrome congênita do VZIK, concluiu-se que o desenvolvimento motor grosso progride marginalmente dos 6 aos 18 meses de idade. Além disso, esses indivíduos também apresentaram alta frequência de paralisia cerebral. Recentemente, em estudo realizado por Takahashi et al. (2021), com objetivo de avaliar a função motora em crianças com síndrome congênita do VZIK de até 3 anos, seus fatores associados e alterações em um intervalo mínimo de 6 meses, foi observado que quase todas as crianças com a síndrome congênita do VZIK apresentavam paralisia cerebral grave e tinham a função motora limitada.

\section{Considerações Finais}

Esta revisão integrativa da literatura demonstrou que há uma alta prevalência de casos de neonatos de mães acometidas por VZIK com paralisia cerebral. Estes dados reforçam a necessidade de serviços de intervenção precoce e planejamento de recursos para apoiar essas famílias em cuidados de saúde e ambientes comunitários no Brasil. Além disso, coortes com longos períodos de acompanhamento sobre o desenvolvimento em longo prazo desses neonatos afetados pela síndrome congênita do Zika são necessárias.

Sendo assim, considero válida a sugestão de que para desenvolver o artigo "Prevalência de paralisia cerebral em neonatos de mães acometidas por Zika vírus: uma revisão integrativa da literatura” em trabalhos futuros seria fazê-lo em outros tipos de estudos, como pesquisa de campo ou revisão sistemática, buscando ampliar esse tema e comprovar as relações patologias que são nele estabelecidas devido a sua grandiosa importância. Também seria opcional o desenvolvimento de projetos em detrimento de tal conteúdo abordado nesse trabalho.

\section{Referências}

Barjas-Castro, M. L., Angerami, R. N., Cunha, M. S., Suzuki, A., Nogueira, J. S., Rocco, I. M., ... \& Addas-Carvalho, M. (2016). Probable transfusion-transmitted Zika virus in Brazil. Transfusion, 56(7), 1684-1688.

Besnard, M., Lastere, S., Teissier, A., Cao-Lormeau, V. M., \& Musso, D. (2014). Evidence of perinatal transmission of Zika virus, French Polynesia, December 2013 and February 2014. Eurosurveillance, 19(13), 20751.

Brasil. Ministério da Saúde. Secretaria de Vigilância em Saúde (2018). Monitoramento integrado de alterações no crescimento e desenvolvimento relacionadas à infecção pelo vírus Zika e outras etiologias infecciosas, até a Semana Epidemiológica 48 de 2017.49 , 1-10. https://portalarquivos2.saude.gov.br/images/pdf/2018/janeiro/30/2018-002.pdf.

Brasil, P., Pereira Jr, J. P., Moreira, M. E., Ribeiro Nogueira, R. M., Damasceno, L., Wakimoto, M., ... \& Nielsen-Saines, K. (2016). Zika virus infection in pregnant women in Rio de Janeiro. New England Journal of Medicine, 375(24), 2321-2334.

Brunoni, D., Blascovi-Assis, S. M., Osório, A. A. C., Seabra, A. G., Amato, C. A. D. L. H., Teixeira, M. C. T. V., ... \& Carreiro, L. R. R. (2016). Microcefalia e outras manifestações relacionadas ao vírus Zika: impacto nas crianças, nas famílias e nas equipes de saúde. Ciência \& Saúde Coletiva, $21,3297-3302$.

Campos, G. S., Bandeira, A. C., \& Sardi, S. I. (2015). Zika virus outbreak, bahia, brazil. Emerging infectious diseases, $21(10), 1885$.

Cao-Lormeau, V. M., Blake, A., Mons, S., Lastère, S., Roche, C., Vanhomwegen, J., ... \& Ghawché, F. (2016). Guillain-Barré Syndrome outbreak associated with Zika virus infection in French Polynesia: a case-control study. The Lancet, 387(10027), 1531-1539.

Carteaux, G., Maquart, M., Bedet, A., Contou, D., Brugières, P., Fourati, S., ... \& Mekontso Dessap, A. (2016). Zika virus associated with meningoencephalitis. New England Journal of Medicine, 374(16), 1595-1596.

Carvalho, A., Brites, C., Mochida, G., Ventura, P., Fernandes, A., Lage, M. L., ... \& Lucena, R. (2019). Clinical and neurodevelopmental features in children with cerebral palsy and probable congenital Zika. Brain and Development, 41(7), 587-594.

Carvalho, A. L. D., Ventura, P., Taguchi, T., Brandi, I., Brites, C., \& Lucena, R. (2020a). Cerebral palsy in children with congenital Zika syndrome: a 2-year neurodevelopmental follow-up. Journal of child neurology, 35(3), 202-207. 
Research, Society and Development, v. 10, n. 7, e6910716335, 2021 (CC BY 4.0) | ISSN 2525-3409 | DOI: http://dx.doi.org/10.33448/rsd-v10i7.16335

Carvalho, A., Sales, H. F., Ventura, P., Gnoatto-Medeiros, M., Brites, C., \& Lucena, R. (2020b). The neurodevelopmental spectrum of congenital Zika infection: a scoping review. Developmental Medicine \& Child Neurology, 62(12), 1356-1362.

Carvalho, A. L. (2020) Cerebral palsy in children with congenital zika syndrome: a 2-year neurodevelopmental follow-up. Journal of Child Neurology,35(3),202-207

Duarte, R. S., Almeida, B. L. F., Sousa, M. N. A., Rolim, L. A. D. M. M. \& Jucá Júnior, F. T. V.(2018) Sequelas da febre Chikungunya e sua interferência na qualidade de vida de indivíduos. Revista Brasileira de Qualidade de Vida (RBQV), 10, 1-14.

Duffy, M. R., Chen, T. H., Hancock, W. T., Powers, A. M., Kool, J. L., Lanciotti, R. S., ... \& Hayes, E. B. (2009). Zika virus outbreak on Yap Island, federated states of Micronesia. New England Journal of Medicine, 360(24), 2536-2543

Einspieler, C., Utsch, F., Brasil, P., Aizawa, C. Y. P., Peyton, C., Hasue, R. H., ... \& GM Zika Working Group. (2019). Association of infants exposed to prenatal Zika virus infection with their clinical, neurologic, and developmental status evaluated via the general movement assessment tool. JAMA network open, 2(1), e187235-e187235

Fauci, A. S., \& Morens, D. M. (2016). Zika virus in the Americas-yet another arbovirus threat. New England journal of medicine, 374(7), 601-604.

Ferreira, H. N. C., Schiariti, V., Regalado, I. C. R., Sousa, K. G., Pereira, S. A., Fechine, C. P. N. D. S., \& Longo, E. (2018). Functioning and disability profile of children with microcephaly associated with congenital Zika virus infection. International journal of environmental research and public health, $15(6), 1107$.

Furtado, J. M., Espósito, D. L., Klein, T. M., Teixeira-Pinto, T., \& da Fonseca, B. A. (2016). Uveitis associated with Zika virus infection. New England Journal of Medicine, 375(4), 394-396.

Hills, S. L., Fischer, M., \& Petersen, L. R. (2017). Epidemiology of Zika virus infection. The Journal of infectious diseases, 216(suppl_10), S868-S874.

Javanian, M., Masrour-Roudsari, J., \& Ebrahimpour, S. Clinical diagnosis challenges in Zika virus infection. Caspian J Intern Med 2018; 9 (4): 416417. Mostafa Javanian (MD), 1 .

Lopes, M. H., Miyaji, K. T., \& Infante, V. (2016). Zika virus. Revista da Associação Médica Brasileira, 62(1), 4-9.

Macnamara, F. N. (1954). Zika virus: a report on three cases of human infection during an epidemic of jaundice in Nigeria. Transactions of the royal society of tropical medicine and hygiene, 48(2), 139-145.

Marques, F. J., Teixeira, M. C., Barra, R. R., de Lima, F. M., Dias, B. L. S., Pupe, C., ... \& Leyser, M. (2019). Children born with congenital Zika syndrome display atypical gross motor development and a higher risk for cerebral palsy. Journal of child neurology, 34(2), 81-85.

Mécharles, S., Herrmann, C., Poullain, P., Tran, T. H., Deschamps, N., Mathon, G., ... \& Lannuzel, A. (2016). Acute myelitis due to Zika virus infection. The Lancet, 387(10026), 1481

Mehrjardi, M. Z., Poretti, A., Huisman, T. A., Werner, H., Keshavarz, E., \& Júnior, E. A. (2017). Neuroimaging findings of congenital Zika virus infection: a pictorial essay. Japanese journal of radiology, 35(3), 89-94.

Melo, A., Gama, G. L., Da Silva Júnior, R. A., De Assunção, P. L., Tavares, J. S., Da Silva, M. B., ... \& De Amorim, M. M. (2020). Motor function in children with congenital Zika syndrome. Developmental Medicine \& Child Neurology, 62(2), 221-226.

Melo, A. S. O., Malinger, G., Ximenes, R., Szejnfeld, P. O., Alves Sampaio, S., \& Bispo de Filippis, A. M. (2016a). Zika virus intrauterine infection causes fetal brain abnormality and microcephaly: tip of the iceberg?. Ultrasound in Obstetrics \& Gynecology, 47(1), 6-7.

Melo, A. S., Aguiar, R., Amorim, M. M., Arruda, M., de Melo, F., Ribeiro, S. T., ... \& Tanuri, A. (2016b). Congenital Zika Virus Infection: Beyond Neonatal Microcephaly. Jama Neurology, 73(12), 1407-1416.

Menezes, E. D. C., Santos, F. A. H., \& Alves, F. L. (2017). Cerebral palsy dysphagia: a systematic review. Revista CEFAC, 19(4), 565-574.

Mlakar, J., Korva, M., Tul, N., Popović, M., Poljšak-Prijatelj, M., Mraz, J., ... \& Avšič Županc, T. (2016). Zika virus associated with microcephaly. New England Journal of Medicine, 374(10), 951-958.

Moore, C. A., Staples, J. E., Dobyns, W. B., Pessoa, A., Ventura, C. V., Da Fonseca, E. B., ... \& Rasmussen, S. A. (2017). Characterizing the pattern of anomalies in congenital Zika syndrome for pediatric clinicians. JAMA pediatrics, 171(3), 288-295.

Mowbray, P. K., Wilkinson, A., \& Tse, H. H. (2015). An integrative review of employee voice: Identifying a common conceptualization and research agenda. International Journal of Management Reviews, 17(3), 382-400.

Pan American Health Organization (2017). Zika-epidemiological report Brazil. 2017. Washington, DC: PAHO/WHO, 2017 http://www2.paho.org/hq/index.php?option=com_docman\&task=doc_view\&gid=35221\&\&Itemid=270.

Pereira, A. M., Araújo Júnior, E., Werner, H., \& Monteiro, D. L. M. (2020). Zika virus and pregnancy: association between acute infection and microcephaly in newborns in the state of Rio de Janeiro, Brazil. Geburtshilfe und Frauenheilkunde, 80(1), 60

Pereira, L. P., de Almeida, A. O. L. C., de Jesus Lima, C. C. O., Santos, J. B., dos Santos Barbosa, M., \& Felzemburgh, R. D. M. (2019). Seizures in newborn with microcephaly associated to Zika virus infection/Crises convulsivas em neonato com microcefalia associada a infeccao pelo Zika virus/Crisis convulsivas en neonato con microcefalia asociada a la infeccion por el virus de Zika. Enfermagem Uerj, 27, NA-NA.

Pessoa, A., van der Linden, V., Yeargin-Allsopp, M., Carvalho, M. D. C. G., Ribeiro, E. M., Braun, K. V. N., ... \& Moore, C. A. (2018). Motor abnormalities and epilepsy in infants and children with evidence of congenital Zika virus infection. Pediatrics, 141(Supplement 2), S167-S179. 
Research, Society and Development, v. 10, n. 7, e6910716335, 2021 (CC BY 4.0) | ISSN 2525-3409 | DOI: http://dx.doi.org/10.33448/rsd-v10i7.16335

Rozé, B., Najioullah, F., Signate, A., Apetse, K., Brouste, Y., Gourgoudou, S., ... \& Cabié, A. (2016). Zika virus detection in cerebrospinal fluid from two patients with encephalopathy, Martinique, February 2016. Eurosurveillance, 21(16), 30205

Russell, K., Hills, S. L., Oster, A. M., Porse, C. C., Danyluk, G., Cone, M., ... \& Brooks, J. T. (2017). Male-to-female sexual transmission of Zika virusUnited States, January-April 2016. Clinical Infectious Diseases, 64(2), 211-213.

Satterfield-Nash, A., Kotzky, K., Allen, J., Bertolli, J., Moore, C. A., Pereira, I. O., ... \& Melo, F. (2017). Health and development at age 19-24 months of 19 children who were born with microcephaly and laboratory evidence of congenital Zika virus infection during the 2015 Zika virus outbreak-Brazil, 2017. MMWR. Morbidity and mortality weekly report, 66(49), 1347

Sharp, T. M., Muñoz-Jordán, J., Perez-Padilla, J., Bello-Pagán, M. I., Rivera, A., Pastula, D. M., ... \& Rivera-García, B. (2016). Zika virus infection associated with severe thrombocytopenia. Clinical Infectious Diseases, 63(9), 1198-1201.

Takahasi, E. H. M., Alves, M. T. S. S. B., Ribeiro, M. R. C., Souza, V. F. P., Simões, V. M. F., Borges, M. C. R. ,..., Silva, A. A. M. D. (2021). Gross motor function in children with Congenital Zika Syndrome. Neuropediatrics, 52(1), 34-43.

Ventura, P. A., Lage, M. L. C., de Carvalho, A. L., Fernandes, A. S., Taguchi, T. B., \& Nascimento-Carvalho, C. M. (2020). Early gross motor development among Brazilian children with microcephaly born right after Zika virus infection outbreak. Journal of Developmental \& Behavioral Pediatrics, 41(2), 134140 . 